Article

\title{
[Ni(1,10-phenanthroline $\left.)_{2}\left(\mathrm{H}_{2} \mathrm{O}\right)_{2}\right]\left(\mathrm{NO}_{3}\right)_{2}$ : A Simple Coordination Complex with a Remarkably Complicated Structure that Simplifies on Heating
}

\author{
Timothy J. Prior ${ }^{1} *$, Apinpus Rujiwatra ${ }^{2}$ and Yothin Chimupala ${ }^{2}$ \\ 1 Department of Chemistry, University of Hull, Cottingham Road, Hull, HU6 7RX, UK \\ 2 Department of Chemistry and Centre for Innovation in Chemistry, Faculty of Science, Chiang Mai \\ University, Chiang Mai 50200, Thailand; E-Mail: apinpus@gmail.com \\ * Author to whom correspondence should be addressed; E-Mail: t.prior@hull.ac.uk; \\ Tel.: +44-1482-466389; Fax: +44-1482-466410.
}

Received: 4 August 2011; in revised form: 31 August 2011 / Accepted: 7 September 2011 / Published: 8 September 2011

\begin{abstract}
Despite the simple chemical formula, [Ni(1,10-phenanthroline $\left.)_{2}\left(\mathrm{H}_{2} \mathrm{O}\right)_{2}\right]\left(\mathrm{NO}_{3}\right)_{2}$, crystallizes with a remarkably complicated 3-D hydrogen bonding supramolecular assembly. The title compound crystallizes in the monoclinic space group $P 2_{1} / c$, with an unusually long $b$ axis and a large cell volume. A huge asymmetric unit has been identified, containing six discrete $\left[\mathrm{Ni}(1,10-\text { phen })_{2}\left(\mathrm{H}_{2} \mathrm{O}\right)_{2}\right]^{2+}$ cations and twelve nitrate anions. Detailed analyses of the crystal structure and $\mathrm{O}-\mathrm{H} \cdots \mathrm{O}$ and $\mathrm{C}-\mathrm{H} \cdots \mathrm{O}$ hydrogen bonding interactions are reported and discussed. In this way the anion-directed assembly of the 3-D structure is illustrated. The thermal and spectroscopic properties of the compound are described. Upon heating to $308 \mathrm{~K}$, the crystal undergoes a phase change to a much simpler structure with a single $\left[\mathrm{Ni}(1,10 \text {-phen })_{2}\left(\mathrm{H}_{2} \mathrm{O}\right)_{2}\right]^{2+}$ cation within the asymmetric unit and unit cell volume one sixth of that at low temperature. Although the crystal decomposed during data collection, it was possible to establish the molecular packing in the high temperature form and relate it to that at low temperature.
\end{abstract}

Keywords: hydrogen bond; supramolecular assembly; single crystal structure; nickel; 1,10-phenanthroline; nitrate; polymorphism 


\section{Introduction}

Remarkably simple coordination complexes can display three dimensional packing that is vastly more intricate than the simple formulae would suggest. The presence of hydrogen bonding, for example, may be responsible for the formation of beautiful patterns of ions. Sometimes this is associated with unexpected complexity within the crystallographic asymmetric unit, resulting from subtle differences in chemically equivalent but crystallographically distinct structural motifs [1,2]. Identification of a large unit cell using weak reflections can prove challenging during data collection. Moreover, structure refinement to a good level of fit is sometimes a difficult task involving extensive use of structure restraints. Subtle differences in similar structural units may nonetheless provide information on different roles of weak interactions and therefore the template function of a structure directing agent. Here we describe a complicated structure derived from rather simple chemical motifs and show that it becomes much less complicated above room temperature.

1,10-phenanthroline (1,10-phen) is a chelating bidentate ligand with notable coordination ability for transition metal cations. In aqueous solution, octahedral complexes of the type $\left[\mathrm{M}(1,10 \text {-phen })\left(\mathrm{H}_{2} \mathrm{O}\right)_{4}\right]^{2+},\left[\mathrm{M}(1,10-\text { phen })_{2}\left(\mathrm{H}_{2} \mathrm{O}\right)_{2}\right]^{2+}$ and $\left[\mathrm{M}(1,10-\text { phen })_{3}\right]^{2+}$ with first-row transition metal cations can be expected $[3,4]$. The strong and predictable binding of 1,10-phen has led to its use as an auxiliary ligand in the design of metal-organic frameworks [5].

The interaction of simple counter ions with metal complexes is not normally crucial in directing the crystal structure of a coordination compound. However, there are examples of so-called "anion-templation" [6]. Here we demonstrate the importance of nitrate in establishing a complex three-dimensional hydrogen bonded array.

In the attempt to grow single crystals of new metal-organic frameworks using the cooperative template effect of 1,10-phen and several anions including nitrate, a 3-D hydrogen bonding supramolecular assembly built up of a large number of crystallographically distinct simple cationic nickel complexes and nitrate counter anions, $\left[\mathrm{Ni}(1,10-\text { phen })_{2}\left(\mathrm{H}_{2} \mathrm{O}\right)_{2}\right]\left(\mathrm{NO}_{3}\right)_{2}$ (1), was obtained. Although several complexes closely related to the title compound are known, in particular, $\left[\mathrm{Ni}(1,10 \text {-phen })_{2}\left(\mathrm{H}_{2} \mathrm{O}\right)_{2}\right]\left(\mathrm{ClO}_{4}\right)_{2} \cdot 0.4 \mathrm{H}_{2} \mathrm{O} \quad[7], \quad\left[\mathrm{Ni}(1,10 \text {-phen })_{2}\left(\mathrm{H}_{2} \mathrm{O}\right)_{2}\right]\left(\mathrm{SO}_{4}\right) \cdot 5.6 \mathrm{H}_{2} \mathrm{O} \quad[8] \quad$ and $\left[\mathrm{Ni}(1,10 \text {-phen })_{2}\left(\mathrm{H}_{2} \mathrm{O}\right)_{2}\right]\left(\mathrm{ZnCl}_{4}\right) \cdot \mathrm{H}_{2} \mathrm{O}$ [9], these other structures are synthesized with tetrahedral anions. The application of nitrate in $\mathbf{1}$ results in a much larger asymmetric unit and a more complicated assembly. Here, the template function of nitrate is illustrated. The synthesis and crystal structure of $\mathbf{1}$ are presented with detailed analysis of the supramolecular assembly. The large number of hydrogen bonding interactions and the established patterns are described and discussed. The thermal and infra-red spectroscopic characterizations are also presented. We demonstrate that the structure persists upon heating to room temperature and at temperatures which ultimately lead to decomposition, a related, but much simpler crystal structure is obtained, that displays similar extended hydrogen-bonding motifs. A change in the structure of transition metal complexes is not unusual (e.g., spin-crossover complexes), but here the change in structure is due to the change in hydrogen-bonding between the cationic complexes and anions, not due to a change in the coordination environment of the metal. 


\section{Results and Discussion}

\subsection{Crystal Structure Description}

The title compound, $\left[\mathrm{Ni}(1,10 \text {-phen })_{2}\left(\mathrm{H}_{2} \mathrm{O}\right)_{2}\right]\left(\mathrm{NO}_{3}\right)_{2} \mathbf{1}$, crystallizes in the monoclinic space group $P 2 / c$ with a large $b$ and cell volume; $a=19.032(1) \AA, b=47.979(3) \AA, c=17.596(1) \AA$, $\beta=116.066(4)^{\circ}, V=14433.3(14) \AA^{3}, Z=24\left(Z^{\prime}=6\right)$. Basic crystal information is contained within Table 1. Good CHN analysis data were obtained for $\mathbf{1}$ as follows. $\mathrm{Ni}_{1} \mathrm{C}_{24} \mathrm{H}_{20} \mathrm{~N}_{6} \mathrm{O}_{8}$ analysis: observed (calculated) \%; C 49.76\% (49.77), H 3.21\% (3.48), N 14.31\% (14.51).

Table 1. Summary of data collection and structure refinement for $\mathbf{1}$.

\begin{tabular}{ll}
\hline CCDC & 793434 \\
Formula & {$\left[\mathrm{Ni}(1,10-\text { phen })_{2}\left(\mathrm{H}_{2} \mathrm{O}\right)_{2}\right]\left(\mathrm{NO}_{3}\right)_{2}$} \\
Formula weight & 579.17 \\
Crystal description & Purple block \\
Crystal system & Monoclinic \\
Space group & $P 2_{1} / c$ \\
$a / \AA$ & $19.032(1)$ \\
$b / \AA$ & $47.979(3)$ \\
$c / \AA$ & $17.596(1)$ \\
$\beta /{ }^{\circ}$ & $116.066(4)$ \\
$V / \AA^{3}$ & $14,433.3(1)$ \\
$Z$ & $24\left(\mathrm{Z}^{\prime}=6\right)$ \\
$\rho_{\text {cald }} / \mathrm{g}$ cm & -3 \\
$T / K$ & 1.599 \\
Radiation $(\lambda / \AA)$ & $120(2)$ \\
Total data collected & Mo $K_{\alpha}(0.71073)$ \\
Unique data & 87822 \\
Parameters refined & 28015 \\
Goodness of fit & 2181 \\
$\mathrm{R}, \mathrm{R}_{\mathrm{w}}($ all data $)$ & 0.965 \\
$\mathrm{R}, \mathrm{R}_{\mathrm{w}}(\mathrm{I}>2 \sigma(\mathrm{I}))$ & $0.1102,0.1714$ \\
\hline
\end{tabular}

The unit cell and space group were determined uniquely from the diffraction data. Although the cell is rather large, it is clear from the diffraction images that this cell does not arise because of incorrect indexing due to twinning or the presence of multiple crystals. The large cell arises for good structural reasons; here small but significant differences in the orientation of $\left[\mathrm{Ni}(1,10-\text { phen })_{2}\left(\mathrm{H}_{2} \mathrm{O}\right)_{2}\right]^{2+}$ cations and associated nitrate anions give rise to the large unit cell.

There are six crystallographically distinct $\left[\mathrm{Ni}(1,10-\text { phen })_{2}\left(\mathrm{H}_{2} \mathrm{O}\right)_{2}\right]^{2+}$ cations in the asymmetric unit, each of which comprises a distorted octahedral $\mathrm{Ni}$ center coordinated by four $\mathrm{N}$ atoms from two 1,10-phen ligands and two $\mathrm{O}$ atoms from the ligated $\mathrm{H}_{2} \mathrm{O}$ molecules. (Figure 1a) There exist, therefore, twelve discrete 1,10-phen and twelve nitrate counter anions in the asymmetric unit. Figure $1 \mathrm{~b}$ shows the coordination environments for the $\left[\mathrm{Ni}(1,10-\mathrm{phen})_{2}\left(\mathrm{H}_{2} \mathrm{O}\right)_{2}\right]^{2+}$ cations and the close neighboring nitrate anions. Atomic numbering is presented for only Ni atoms in this figure for clarity, but ORTEP 
representations of each unique $\left[\mathrm{Ni}(1,10-\text { phen })_{2}\left(\mathrm{H}_{2} \mathrm{O}\right)_{2}\right]^{2+}$ cation are provided separately in the Supplementary Information.

Figure 1. (a) A portion of the asymmetric unit showing the coordination about Ni1. Atoms are drawn as 50\% thermal ellipsoids. (b) An ORTEP diagram for 1 showing the whole asymmetric unit. The drawings are shown with partial atomic numbering scheme and $30 \%$ thermal ellipsoids. (Detailed ORTEP diagrams of each cation can be found in the Supplementary Information.)

(a)

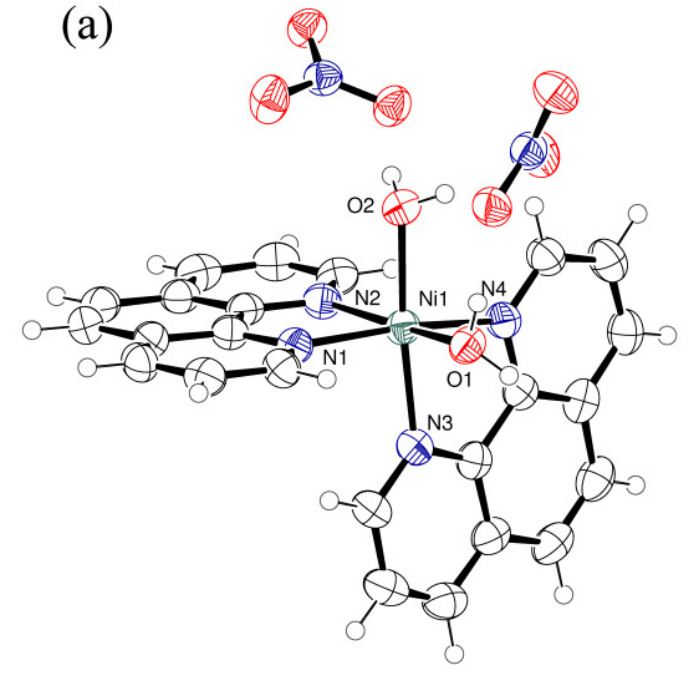

(b)

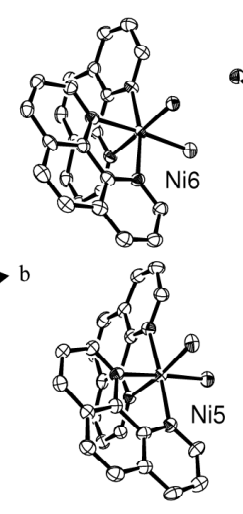

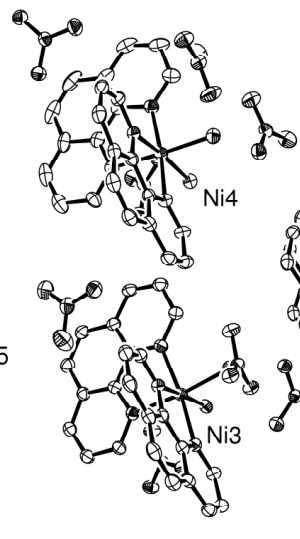

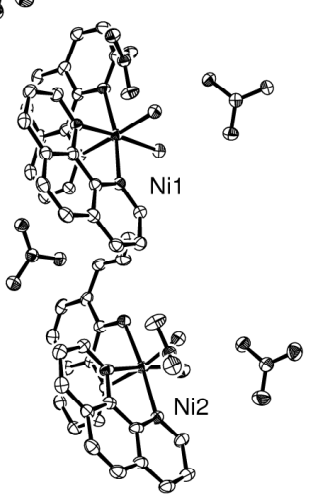

The 1,10-phen ligands adopt the expected chelating mode of coordination with the chelating angles in the range $79.41-80.29^{\circ}$ with a mean $79.90(11)^{\circ}$. It is also common that two 1,10 -phen ligands of the same cationic cluster adopt cis configuration with any two co-centric molecular planes set nearly orthogonal; here the angles vary between $83.68^{\circ}$ and $89.28^{\circ}$. The conformation about each $\mathrm{Ni}$ atom can therefore be described as symmetrical-cis (sy-cis) configuration. The six bond lengths about each nickel cation are rather similar; the Ni-N bond lengths lie in the range 2.065(3)-2.101(3) $\AA$ with a mean of $2.082 \AA$ and standard deviation $0.009 \AA$, while Ni-O bond lengths vary between $2.058(3)-2.102(3) \AA$ with a mean of $2.080 \AA$ and a standard deviation $0.014 \AA$. Selected bond lengths and angles are listed in Table 2. The as-described configuration, bond lengths and angles are in good agreement with those reported for the closely related Ni-1,10-phen structures [7-9]. According to the refined bond lengths and the assumption for parameters $R_{0}\left(\mathrm{Ni}^{\mathrm{II}}-\mathrm{O}^{-\mathrm{II}}\right)=1.654, R_{0}\left(\mathrm{Ni}^{\mathrm{II}}-\mathrm{N}^{-\mathrm{II}}\right)=1.700$, and $b=0.370[10,11]$, the bond valence sums have been calculated and the results confirm a divalent state for $\mathrm{Ni}$ atoms: 2.058, 2.050, 2.060, 2.066, 2.054 and 2.061 for Ni1, Ni2, Ni3, Ni4, Ni5 and Ni6, respectively. The presence of divalent nickel within the $\left[\mathrm{Ni}^{\mathrm{II}}(1,10-\mathrm{phen})_{2}\left(\mathrm{H}_{2} \mathrm{O}\right)_{2}\right]^{2+}$ cation is in accordance with the crystallographic observation of two nitrate anions for every nickel complex. 
Table 2. Selected bond lengths $(\AA)$ and angles $\left({ }^{\circ}\right)$ for low temperature structure of $\mathbf{1}$.

\begin{tabular}{lrlrlr}
\hline Bond length $(\AA)$ & & & & & \\
\hline Ni1-O1 & $2.081(3)$ & Ni2-O3 & $2.102(3)$ & Ni3-O5 & $2.068(3)$ \\
Ni1-O2 & $2.060(2)$ & Ni2-O4 & $2.082(3)$ & Ni3-O6 & $2.078(3)$ \\
Ni1-N1 & $2.081(3)$ & Ni2-N5 & $2.073(3)$ & Ni3-N9 & $2.085(3)$ \\
Ni1-N2 & $2.089(3)$ & Ni2-N6 & $2.084(3)$ & Ni3-N10 & $2.081(3)$ \\
Ni1-N3 & $2.074(3)$ & Ni2-N7 & $2.093(3)$ & Ni3-N11 & $2.089(3)$ \\
Ni1-N4 & $2.101(3)$ & Ni2-N8 & $2.065(3)$ & Ni3-N12 & $2.083(3)$ \\
Ni4-O7 & $2.096(3)$ & Ni5-O9 & $2.081(3)$ & Ni6-O11 & $2.058(3)$ \\
Ni4-O8 & $2.072(3)$ & Ni5-O10 & $2.100(3)$ & Ni6-O12 & $2.076(3)$ \\
Ni4-N13 & $2.062(3)$ & Ni5-N17 & $2.073(3)$ & Ni6-N21 & $2.086(3)$ \\
Ni4-N14 & $2.086(3)$ & Ni5-N18 & $2.090(3)$ & Ni6-N22 & $2.094(3)$ \\
Ni4-N15 & $2.085(3)$ & Ni5-N19 & $2.082(3)$ & Ni6-N23 & $2.083(3)$ \\
Ni4-N16 & $2.079(3)$ & Ni5-N20 & $2.068(3)$ & Ni6-N24 & $2.085(3)$ \\
\hline Bond Angles $\left({ }^{\circ}\right)$ & & & & & \\
\hline N4-Ni1-O1 & $95.85(11)$ & N9-Ni3-O6 & $90.12(11)$ & N17-Ni5-O9 & $89.52(12)$ \\
N1-Ni1-O1 & $91.12(11)$ & N11-Ni3-O6 & $94.84(11)$ & N20-Ni5-O9 & $95.80(12)$ \\
N1-Ni1-N2 & $80.29(12)$ & N10-Ni3-N9 & $80.29(12)$ & N17-Ni5-N18 & $79.83(12)$ \\
N2-Ni1-N4 & $93.30(12)$ & N10-Ni3-N11 & $95.23(12)$ & N19-Ni5-N18 & $95.39(12)$ \\
O2-Ni1-N3 & $174.85(11)$ & O5-Ni3-N12 & $174.49(12)$ & O10-Ni5-N19 & $172.53(12)$ \\
N5-Ni2-O3 & $94.27(12)$ & N13-Ni4-O7 & $94.60(12)$ & O11-Ni6-N24 & $95.66(11)$ \\
N8-Ni2-O3 & $87.56(11)$ & N16-Ni4-O7 & $88.45(12)$ & O12-Ni6-N24 & $98.32(12)$ \\
N8-Ni2-N6 & $98.55(12)$ & N13-Ni4-N14 & $79.89(13)$ & N24-Ni6-N22 & $91.22(12)$ \\
N5-Ni2-N6 & $80.05(12)$ & N16-Ni4-N14 & $97.57(13)$ & N21-Ni6-N22 & $79.97(12)$ \\
O4-Ni2-N7 & $169.82(12)$ & O8-Ni4-N15 & $170.02(12)$ & O11-Ni6-N23 & $174.40(12)$ \\
\hline & & & & & \\
\hline
\end{tabular}

Three other closely related compounds built up of identical cationic complex as $\mathbf{1}$ have been previously reported, including $\left[\mathrm{Ni}(1,10 \text {-phen })_{2}\left(\mathrm{H}_{2} \mathrm{O}\right)_{2}\right]\left(\mathrm{ClO}_{4}\right)_{2} \cdot 4 \mathrm{H}_{2} \mathrm{O}$ [7], [Ni(1,10-phen $\left.)_{2}\left(\mathrm{H}_{2} \mathrm{O}\right)_{2}\right]$ $\left(\mathrm{SO}_{4}\right) \cdot 5.6 \mathrm{H}_{2} \mathrm{O}[8]$ and $\left[\mathrm{Ni}(1,10 \text {-phen })_{2}\left(\mathrm{H}_{2} \mathrm{O}\right)_{2}\right]\left(\mathrm{ZnCl}_{4}\right) \cdot 0.4 \mathrm{H}_{2} \mathrm{O}$ [9]. These structures have much simpler asymmetric units that comprise either one-half or a single cationic cluster with counter anions of tetrahedral geometry. The patterns of hydrogen bonding interactions and the appearance of $\pi-\pi$ interactions are similar in these structures. The employment of the nitrate anion with unit charge instead of the divalent anions in the previously reported compounds results, at a first glance, in a different cation-to-anion ratio; 1:2 in 1 compared with 1:1 in two of the previously reported structures. The triangular planar geometry of the nitrate can, in addition, arrange more flexibly in smaller space compared to the tetrahedral ones. The hydrogen bonding analysis listed in Table 3 reveals that every nitrate is hydrogen bonded to the neighboring cationic clusters in such a way that the spatial 
orientation of the clusters is directed through the hydrogen bonding interactions. Figure 2 shows the $\mathrm{O}-\mathrm{H} \cdots \mathrm{O}$ interactions about each cluster formed between the $\mathrm{O}-\mathrm{H}$ groups of the water ligated to the $\left[\mathrm{Ni}^{\mathrm{II}}(1,10 \text {-phen })_{2}\left(\mathrm{H}_{2} \mathrm{O}\right)_{2}\right]^{2+}$ cations and the $\mathrm{O}$ atoms of the nearby nitrate anions. It is clear that subtle changes in the orientation of each $\left[\mathrm{Ni}^{\mathrm{II}}(1,10-\text { phen })_{2}\left(\mathrm{H}_{2} \mathrm{O}\right)_{2}\right]^{2+}$ cation facilitate hydrogen bonding to the nitrate anions which themselves occupy positions designed to maximize interactions with the surrounding cations. Relatively short $\pi-\pi$ distances between the 1,10-phen ligands of different complexes in the range $3.45 \AA$ to $3.5 \AA$ are present.

Table 3. Hydrogen bond geometry $\left(\AA{ }^{\circ}\right)$ for low temperature structure of $\mathbf{1}$.

\begin{tabular}{|c|c|c|c|}
\hline $\mathrm{D}-\mathrm{H} \cdots \mathrm{A}$ & $\mathrm{H} \cdots \mathrm{A}$ & $\mathrm{D} \cdots \mathrm{A}$ & $\angle \mathrm{D}-\mathrm{H} \cdots \mathrm{A}$ \\
\hline $\mathrm{O} 1-\mathrm{H} 1 \mathrm{~A} \cdots \mathrm{O} 201^{i}$ & $2.02(3)$ & $2.875(4)$ & $174(5)$ \\
\hline $\mathrm{O} 1-\mathrm{H} 1 \mathrm{~B} \cdots \mathrm{O} 102^{i}$ & $1.90(2)$ & $2.757(3)$ & $172(5)$ \\
\hline $\mathrm{O} 2-\mathrm{H} 2 \mathrm{~A} \cdots \mathrm{O} 100$ & $1.89(4)$ & $2.720(4)$ & $168(4)$ \\
\hline $\mathrm{O} 2-\mathrm{H} 2 \mathrm{~A} \cdots \mathrm{O} 101$ & $2.25(5)$ & $3.175(4)$ & $135(4)$ \\
\hline $\mathrm{O} 2-\mathrm{H} 2 \mathrm{~B} \cdots \mathrm{O} 202^{i}$ & $1.86(3)$ & $2.680(4)$ & $176(5)$ \\
\hline O3-H3A $\cdots \mathrm{O} 160^{i}$ & 2.01(4) & $2.783(4)$ & $150(5)$ \\
\hline O3-H3B $\cdots \mathrm{O} 180^{i}$ & $2.20(4)$ & $3.002(4)$ & $157(5)$ \\
\hline $\mathrm{O} 3-\mathrm{H} 3 \mathrm{~B} \cdots \mathrm{O} 182^{i}$ & $2.31(6)$ & $3.048(5)$ & $146(4)$ \\
\hline $\mathrm{O} 4-\mathrm{H} 4 \mathrm{~A} \cdots \mathrm{O} 181$ & $1.87(3)$ & $2.688(4)$ & $168(4)$ \\
\hline O4-H4B $\cdots \mathrm{O} 160^{i}$ & $1.89(3)$ & $2.738(4)$ & $167(4)$ \\
\hline O5-H5A ‥O132 & $1.87(3)$ & $2.692(4)$ & $165(5)$ \\
\hline $\mathrm{O} 5-\mathrm{H} 5 \mathrm{~B} \cdots \mathrm{O} 121$ & $1.87(4)$ & $2.707(4)$ & $167(3)$ \\
\hline O6-H6A ‥O152 & $1.892(19)$ & $2.750(3)$ & $176(4)$ \\
\hline O6-H6B ‥O120 & $1.94(3)$ & $2.860(4)$ & $176(3)$ \\
\hline $\mathrm{O} 7-\mathrm{H} 7 \mathrm{~A} \cdots \mathrm{O} 170$ & $1.94(3)$ & $2.795(4)$ & $157(4)$ \\
\hline O7-H7B $\cdots \mathrm{O} 190$ & $1.94(3)$ & $2.941(4)$ & $169(5)$ \\
\hline O7-H7B ‥O191 & $1.99(3)$ & $3.092(5)$ & $133(3)$ \\
\hline 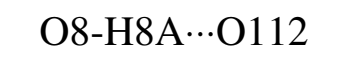 & $1.87(3)$ & $2.687(4)$ & $167(4)$ \\
\hline O8-H8B $\cdots \mathrm{O} 170$ & $1.89(3)$ & $2.729(4)$ & $164(5)$ \\
\hline O9-H9A …O192 & $1.88(3)$ & $2.683(4)$ & $155(3)$ \\
\hline O9-H9B $\cdots \mathrm{O} 221$ & $1.91(3)$ & $2.764(4)$ & $163(5)$ \\
\hline $\mathrm{O} 10-\mathrm{H} 10 \mathrm{~A} \cdots \mathrm{O} 221$ & $1.91(3)$ & $2.741(4)$ & $156(4)$ \\
\hline O10-H10B $\cdots$ O $110^{i i}$ & $2.15(4)$ & $2.980(5)$ & $155(3)$ \\
\hline O10-H10B $\cdots$ O111 $1^{i i}$ & $2.30(3)$ & $3.049(4)$ & $142(3)$ \\
\hline 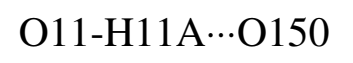 & $1.89(4)$ & $2.724(4)$ & $174(4)$ \\
\hline 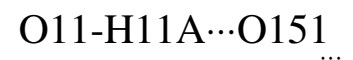 & $2.54(3)$ & $3.144(4)$ & $130(3)$ \\
\hline O11-H11B $\cdots$ O140 & $1.86(3)$ & $2.722(4)$ & $175(5)$ \\
\hline $\mathrm{O} 12-\mathrm{H} 12 \mathrm{~A} \cdots \mathrm{O} 141^{i i i}$ & $1.94(3)$ & $2.852(4)$ & $170(5)$ \\
\hline $\mathrm{O} 12-\mathrm{H} 12 \mathrm{~B} \cdots \mathrm{O} 131^{i}$ & $1.882(19)$ & $2.729(4)$ & $164(4)$ \\
\hline
\end{tabular}

Symmetry equivalent atoms are generated by these operators: $i=x, 0.5-y,-0.5+z ; i i=x, y$, $1+z ; i i i=1-x,-y,-1+z$. 
Figure 2. Hydrogen bonding patterns (dotted lines) displayed by the $\left[\mathrm{Ni}(1,10-\mathrm{phen})_{2}\right.$ $\left.\left(\mathrm{H}_{2} \mathrm{O}\right)_{2}\right]^{2+}$ cations in the 1-D hydrogen bonding chains of four different chains: (a) $A$ (b) $B$ (c) $C$ and (d) $D ; i=x, 0.5-y,-0.5+z ; i i=x, 0.5-y, 0.5+z ; i i i=x, y,-1+z ; i v=1-x,-y,-z$; $v=1-x,-y, 1-z$. Hydrogen bonds are drawn as dashed lines.
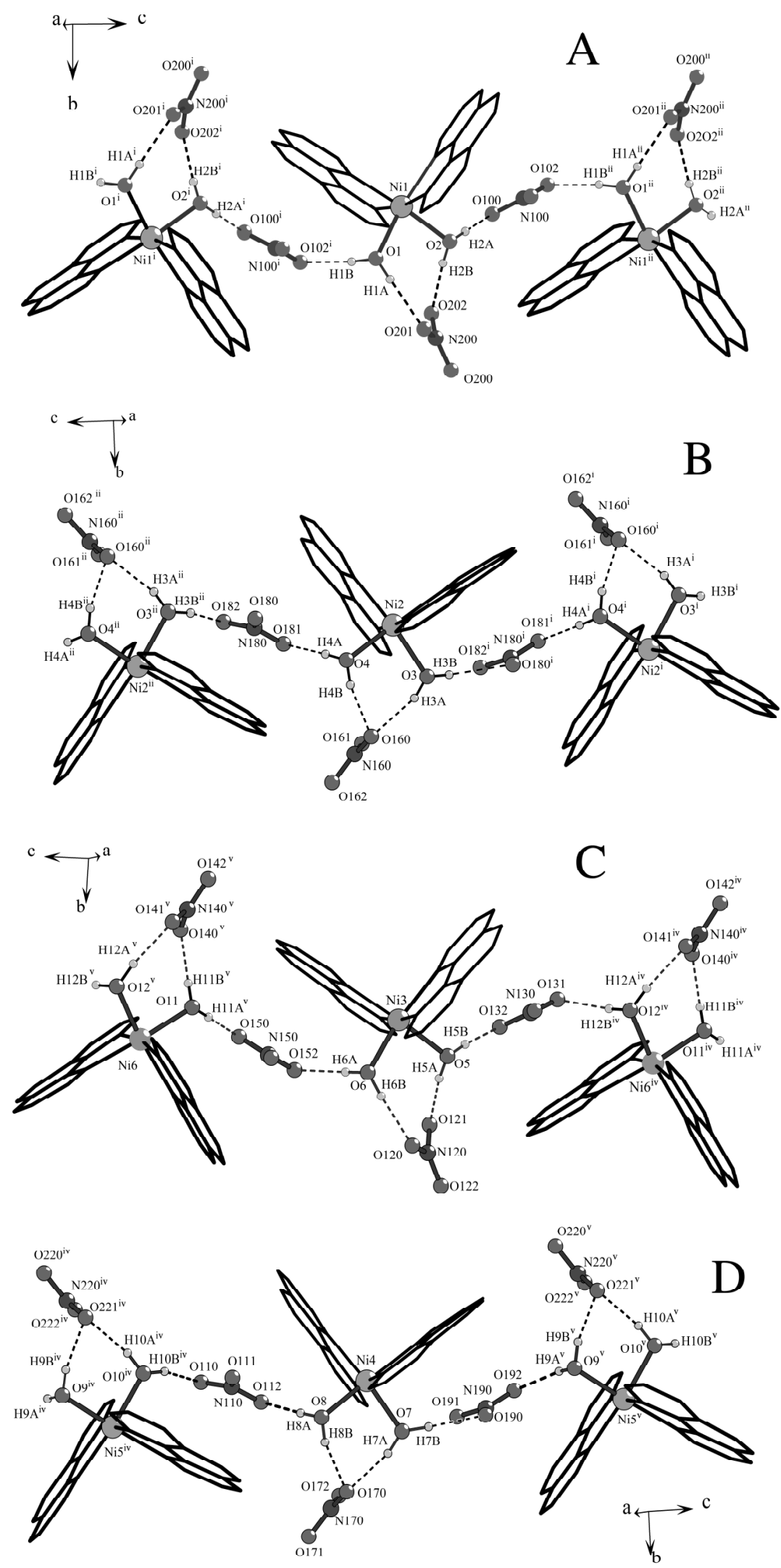
The structure of $\mathbf{1}$ is therefore remarkable for the beautiful chains, formed from classical $\mathrm{O}-\mathrm{H} \cdots \mathrm{O}$ hydrogen bonds, which run parallel to the crystallographic $c$ axis. Within 1 there are four independent types of chain which, while similar, have subtle differences. These chains are illustrated $A, B, C$, and $D$ in Figure 2. In each case, the repeat unit has length 17.596(1) $\AA$, which is a unit translation along $c$. These can be classified into two pairs of chains; $A \& B$ and $C \& D$. For each of the first pair, identical metal complexes are assembled into chains through hydrogen bonding by nitrate anions. For the second pair, while each chain has the same basic arrangement of ions, two different metal complexes make up each chain, bridged by hydrogen bonds to nitrate. However, there is additional nitrate bound by hydrogen bonds which decorates each of the chains, and the differences in this decoration make each chain unique. These chains are described further below.

Complexes of Ni1 are assembled into saw tooth chains through classical hydrogen bonds between bound water and nitrate with central atom N100 forming a $C_{2}^{2}(8)$ hydrogen bonding pattern (chain $A$ ). Successive complexes are related by the $c$-glide operation. The chain can be labeled as having an $M n M n$ repeat in which there is only one crystallographically unique metal complex (signified $M$ ) and one unique nitrate (signified $n$ ). This chain is further decorated by nitrate centered on N200 which does not form part of the chain link. This nitrate forms classical hydrogen bonds to the two bound water molecules on Ni1 through $\mathrm{O} 201$ and $\mathrm{O} 202$ forming an embrace that may be described as $R_{2}^{2}(8)$ using the Graph Set Notation [12]. The second chain $(B)$ is composed of complexes of Ni2 and nitrate (N180) and is extremely similar to the first, presenting a $C_{2}^{2}(8)$ pattern, differing only in the way it is decorated by further nitrate. Adjacent nickel complexes are again related by the $c$-glide operation and the chain can be labeled MnMn as for the first. However, while there is a further nitrate anion (central atom N160) bound to this chain at every metal centre through hydrogen bonding, it does so through only one $\mathrm{O}$ atom. In contrast to chain $\mathrm{A}$, each bound water is still involved in localizing this nitrate, so this embrace can be described by the different graph set, $R_{2}^{1}(6)$.

A third independent chain (labeled $C$ ) is formed from two metal complexes Ni3 and Ni6 which are bridged by hydrogen bonds from two nitrates (N130 and N150). Each of the four species involved in the formation of this chain is crystallographically unique, but there is a regular alternating arrange of metal complexes and nitrates to give a chain with form $M n M^{\prime} n^{\prime} M n M^{\prime} n^{\prime}$. The formal description of this chain as $C_{4}^{4}(16)$ demonstrates the larger crystallographically unique repeat unit. The chain has a very similar form to the two described above but is not generated by the $c$-glide. This chain is decorated by two unique nitrate groups: the nitrate with central atom N120 forms an $R_{2}^{2}(8)$ embrace at Ni3, which the nitrate $\mathrm{N} 140$ binds through a $R_{2}^{2}(8)$ ring at Ni6.

Finally, the fourth chain, labeled $D$, is similar to the third; it is composed of the complexes Ni4 and Ni5 bridged by classical hydrogen bonds to the nitrates N110 and N190. These four symmetry independent units alternate to generate a chain with form $M n M^{\prime} n^{\prime} M n M^{\prime} n^{\prime}$ running parallel to the $c$-axis with notation $C_{4}^{4}(16)$. This is decorated by two independent nitrate anions that bind through one oxygen atom only, forming $R_{2}^{1}(6)$ embraces. The nitrate N170 forms two hydrogen bonds at Ni4 through the oxygen O170. Very similarly, the nitrate N220 binds at Ni5 forming two hydrogen bonds through oxygen $\mathrm{O} 221$.

The subtle differences in the nitrate orientation and associated hydrogen bonds give rise to the complicated crystallographic asymmetric unit. The structure arrangement adopted by the metal complexes and nitrate make it possible for four different hydrogen bonded chains to form that rely 
upon small differences in orientation. The choice of data collection strategy (two overlapping datasets of different counting times) was important because obtaining reliable estimates of the intensity of the weak reflections is important in determining small differences in groups of light atoms such as nitrate. We note also that the interpretation of the hydrogen bonding present was greatly assisted by the presence of electron density corresponding to hydrogen atoms within final difference Fourier maps.

The hydrogen bonding chains are further packed with regular alternation, leading to the $A B A B$ and $C D C D$ layer registries in the direction of $a$. While there are no $\mathrm{O} \cdots \mathrm{H}$ distances indicative of classical hydrogen bonds, these chains are held together by a very large number of $\mathrm{C}-\mathrm{H} \cdots \mathrm{O}$ non-classical hydrogen bonding interactions between nitrate and 1,10-phen. Applying the Jeffrey criterion for hydrogen bonds [13], there are 46 independent $\mathrm{C}-\mathrm{H} \cdots \mathrm{O}$ hydrogen bonds with a mean $\mathrm{H} \cdots \mathrm{O}$ distance of $2.47 \AA$ and standard deviation $0.08 \AA$. These generate a 2-D layered network in the $a c$ plane, as shown in Figure 3. Full details of these interactions are given within the Supplementary Information. The 3-D hydrogen bonding supramolecular assembly with the (CDCD-ABAB-CDCD-DCDC-BABA-DCDC$)_{n}$ stacking sequence is further generated according to the $2_{1}$ and $\overline{1}$ operations in the direction of $b$ (Figure 4). The subtle differences in both number and spatial orientation of weak but abundant $\mathrm{C}-\mathrm{H} \cdots \mathrm{O}$ hydrogen bonding interactions apparently depend on the arrangement of the neighboring nitrate anions. The assembly directing function of the nitrate anions which also account for the minor deviations in the asymmetric $\left[\mathrm{Ni}(1,10-\text { phen })_{2}\left(\mathrm{H}_{2} \mathrm{O}\right)_{2}\right]^{2+}$ cations is therefore illustrated.

Figure 3. Diagrammatic illustrations depicting the packing sequence of the 1-D hydrogen bonding chains to form 2-D hydrogen bonding layers of (a) $A B A B$ and (b) $C D C D$ registries in the $a c$ plane. The sheets of different types are colored cyan and red for easy comparison with Figure 4.

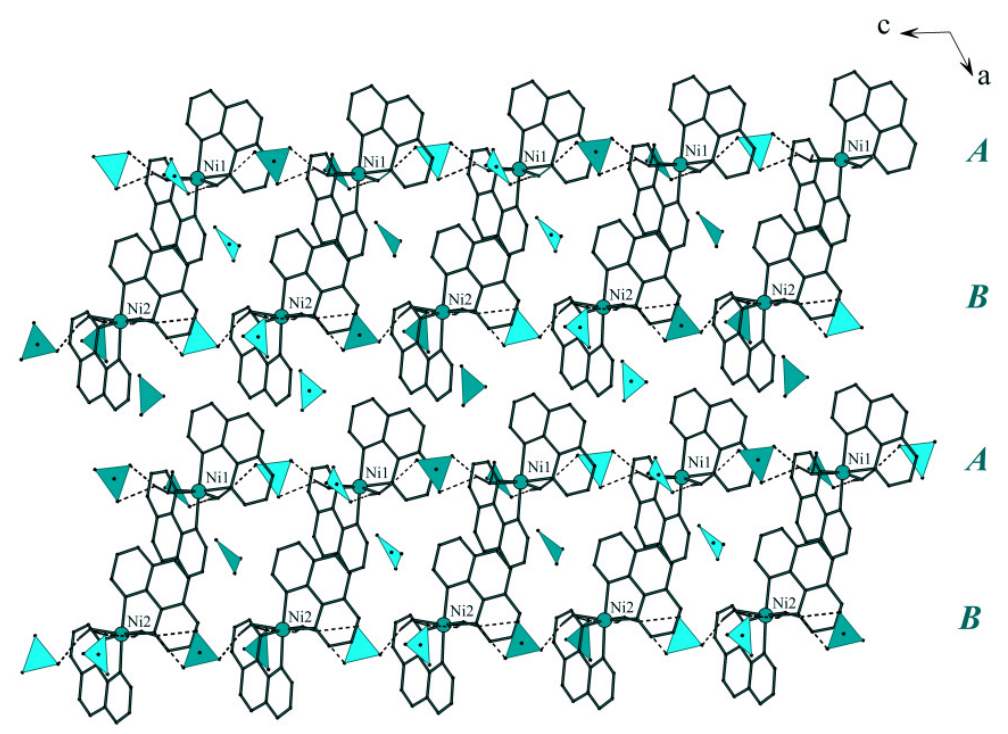

(a) 
Figure 3. Cont.

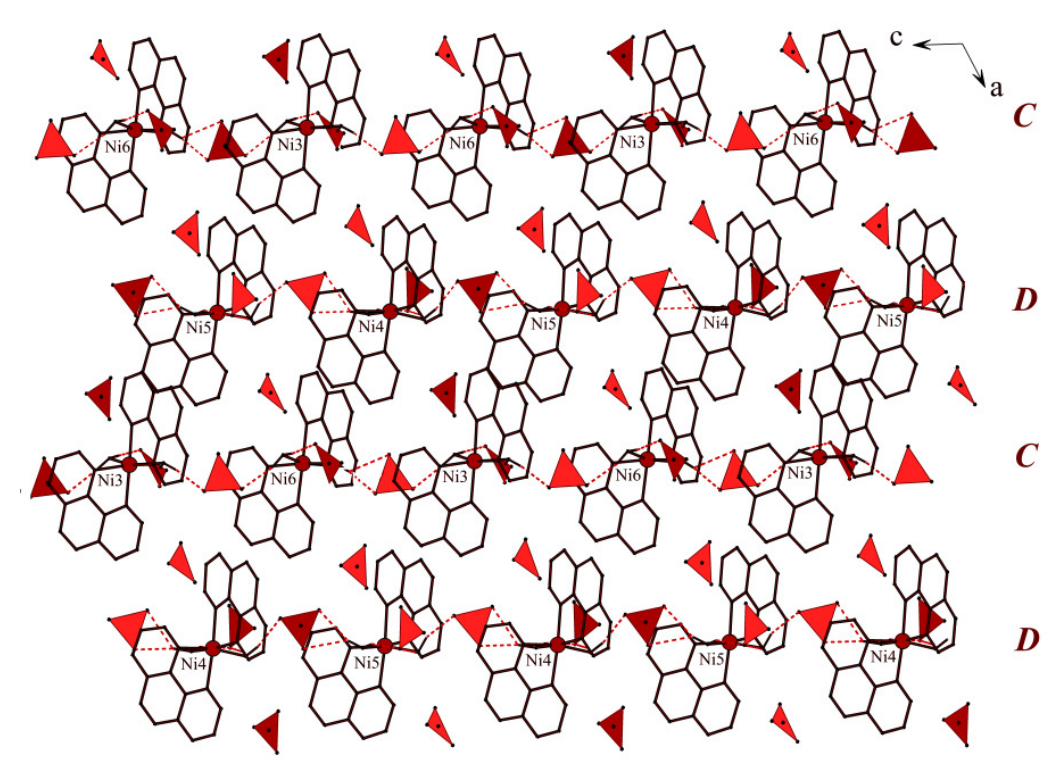

(b)

Figure 4. The formation of 3-D supramolecular assembly in $\mathbf{1}$.

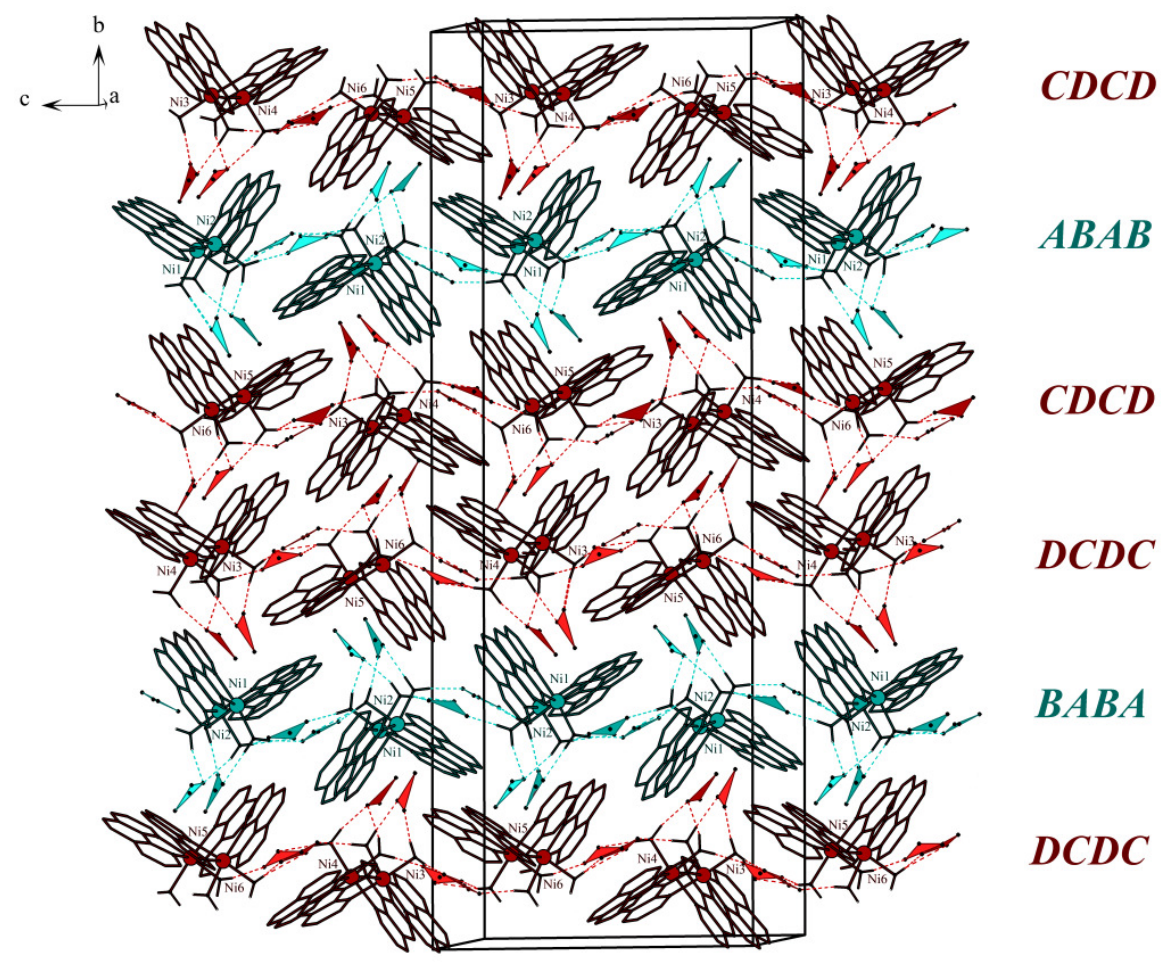

We are confident in the correctness of the structure solution, despite the large asymmetric unit for a number of reasons. It was not necessary to apply restraints to the bond lengths within the metal complexes, only to restrain the $\mathrm{O}-\mathrm{H}$ distances in water to suitable values. The root mean square ( $r m s$ ) deviation of pseudo-equivalent bonds lengths is small, which is a good indicator that the structure is reliable. Full details of all of the bond lengths are given in the Supplementary Information. The final difference Fourier maps after heavy atoms had been located provided information about the location of 
hydrogen atoms present. In this case the refinement of hydrogen atom positions subject to sensible restraints proceeded smoothly. The location and refinement of hydrogen atoms has been cited as a reliable indicator of a correct structure [14]. Although the structure displays pseudosymmetry, there are good structural reasons why a smaller asymmetric unit is inappropriate, namely the four independent hydrogen-bonding chains, which arise from differences in the orientation of the cations and nitrate. The six sheets of chains in the $a c$ plane represented in Figure 3 that are stacked along $b$ are close to being related by a translation of $b / 3$ ( $2 b / 3$ as identified by PLATON). However this is a rather poorly satisfied psuedosymmetry operation; the differences in the nature of the chains and their decoration enforce the need for a long $b$ axis. It is also notable that the six independent cations within the asymmetric unit are related in pairs by a translation of 0.45 along the $a$ direction. These are Ni1\&Ni2, Ni3\&Ni4, Ni5\&Ni6 as can be seen in Figure 1. The nitrate positions and orientations are important in breaking this psuedosymmetry; careful inspection of the pairs of metal complexes down [100] reveals that they do not overlie due to significant rotation. The Supplementary Information contains a plot of the six independent $\left[\mathrm{Ni}(1,10 \text {-phen })_{2}\left(\mathrm{H}_{2} \mathrm{O}\right)_{2}\right]^{2+}$ cations overlaid under the action of the pseudosymmetry operations present. There is a clear deviation from a truly symmetric array.

\subsection{Spectroscopic Characterization}

The FT-IR spectrum of $\mathbf{1}$ and a complete list of assignments are provided within the Supplementary Information. The FT-IR spectrum of $\mathbf{1}$ shows characteristic vibrational bands of each of the ligated species [15-18], which is in good agreement with the crystal structure obtained at $120 \mathrm{~K}$. The strong, broad absorption centered on $1382 \mathrm{~cm}^{-1}$ with three shoulders at 1359,1341 and $1305 \mathrm{~cm}^{-1}$ can be assigned to asymmetric stretching vibration $\left(v_{3}\right)$ of the nitrate anions present. The local $D_{3 h}$ symmetry of the non-coordinated nitrate, means the strong absorption due to the out-of-plane $v_{2}$ and in-plane $v_{4}$ deformations are clearly visible at 847 and $726 \mathrm{~cm}^{-1}$, respectively. The presence of a weak band at $1051 \mathrm{~cm}^{-1}$, which can be due to the otherwise IR-inactive symmetric stretching $v_{1}$ suggests the involvement of the nitrate in hydrogen bonding, in accordance with the structure of $\mathbf{1}$ described above. The broad and strong band centered about $3220 \mathrm{~cm}^{-1}$ confirms the existence of the ligated water. There is clear evidence for coordinated 1,10-phen within the spectrum, although peaks due to this are much weaker than those from nitrate. The band at $1516 \mathrm{~cm}^{-1}$ and the less intense band at $1494 \mathrm{~cm}^{-1}$ and the other weak band at $775 \mathrm{~cm}^{-1}$ with a shoulder at $785 \mathrm{~cm}^{-1}$ are clear in the spectrum. These bands are characteristic of the 1,10-phen within coordination complexes.

\subsection{Thermal Behavior}

Upon heating under nitrogen, 1 loses mass in two well-defined steps and then decomposes over a very broad temperature range. Between 80 and $155^{\circ} \mathrm{C}$, the sample loses an amount of mass in good agreement with the loss of two molecules of water. Thereafter, the composition $\mathrm{Ni}(1,10-\mathrm{phen})_{2}\left(\mathrm{NO}_{3}\right)_{2}$ is remarkably stable from $155^{\circ} \mathrm{C}$ to $365{ }^{\circ} \mathrm{C}$. X-ray diffraction data collected from a sample heated to $220{ }^{\circ} \mathrm{C}$ show this phase does not display long range order. At about $365^{\circ} \mathrm{C}$ there is a very sharp mass loss to generate a phase with $\mathrm{RMM} \approx 320 \mathrm{~g} \mathrm{~mol}^{-1}$ which is likely to be due to loss of 1,10 -phen and loss/decomposition of nitrate. Above $370{ }^{\circ} \mathrm{C}$, the sample loses mass steadily up to $1000{ }^{\circ} \mathrm{C}$, until it 
approaches the final endpoint, NiO. Thermogravimetry and differential scanning calorimetry data are contained within the Supplementary Information.

\subsection{X-ray Diffraction Studies of High Temperature Phases}

The initial data collection was carried out at $120 \mathrm{~K}$ to minimize atomic thermal motion. We thought it possible that the structure might convert to a much simpler one at higher temperatures, particularly where there is sufficient thermal energy for the nitrates to rearrange by rotation. A single crystal of 1 was examined at $291 \mathrm{~K}$ and the structure determined by X-ray diffraction. The structure remained essentially unchanged upon warming to $291 \mathrm{~K}$ with space group $P 2_{1} / c$. The unit cell parameters at this temperature were $a=19.1244(13) \AA, b=48.654(4) \AA, c=17.9030(12) \AA, \beta=116.949(5)^{\circ}$, $V=14,849.3(19) \AA^{3}$. The cell shows a $2.88 \%$ increase in volume from $120 K$ to $291 K$. At this higher temperature the scattering of the crystal was markedly weaker and the final solution poorer so that hydrogen atoms were not apparent in final difference Fourier maps. There are small changes in the structure upon heating, but the large cell is still uniquely identified and there is no evidence for the asymmetric unit becoming closer to a simpler atomic arrangement.

Heating the crystal to $333 \mathrm{~K}$ in an attempt to collect data led to catastrophic breakdown of the crystal. This was apparent from the diffraction images and from the cracking of the crystal into myriad fragments. However, it was possible to collect a limited amount of useful diffraction data from a crystal held at $308 \mathrm{~K}$. At this temperature, the crystal ultimately decomposed during data collection, but it was possible to collect twenty diffraction images of reasonable quality before the sample ceased to be crystalline. These twenty images showed evidence of a dominant, crystalline domain within the sample without the long $b$-axis of $\mathbf{1}$ (See Supplementary Information). Spots due to this domain were relatively sharp and it was possible to index the unit cell of this phase, hereafter labeled $\mathbf{1 b}$. The initial unit cell obtained was monoclinic with parameters $a=9.565(5), b=16.246(9), c=15.979(6) \AA$ and $\beta=95.06(3)^{\circ}$; the unit cell volume was found to be $2474 \AA^{3}$. Systematic absences in the data suggested the space group was $P 2_{1} / n$. The unit cell volume is almost exactly one sixth of the volume of $\mathbf{1}$ at 291 $K$. Furthermore this unit cell has very similar dimensions to one reported by Liu et al. for diaqua(1,10-phenanthrolin-2-ol) nickel(II) dinitrate at $298 \mathrm{~K}$ [19], which crystallises in $P 2_{1} / n$ with a single metal complex in the asymmetric unit. The components of this compound are extremely similar to those of $\mathbf{1 b}$, differing only in the intramolecular hydrogen-bonding about the $\mathrm{Ni}^{2+}$ cation. This information strongly suggests that $\mathbf{1 b}$ is a high temperature form of $\mathbf{1}$ which crystallises with a single $\left[\mathrm{Ni}(1,10 \text {-phen })_{2}\left(\mathrm{H}_{2} \mathrm{O}\right)_{2}\right]^{2+}$ cation in the asymmetric unit (Figure 5). It is possible to reset $\mathbf{1 b}$ into the standard setting of space group $14, P 2_{1} / c$, with cell parameters $a=9.565(5) \AA, b=16.246(9) \AA$, $c=17.864(7) \AA$ and $\beta=116.97(3)^{\circ}$. The relationship between the unit cells of $\mathbf{1}$ and $\mathbf{1 b}$ then becomes apparent: $a^{\prime}=a / 2 ; b^{\prime}=b / 3 ; c^{\prime}=c ; \beta^{\prime}=\beta$. The sixfold reduction in unit cell volume does not alter the symmetry but leads to a greatly simplified asymmetric unit. It is important to note that there was no evidence in the diffraction images for the presence of the larger cell at $308 \mathrm{~K}$. 
Figure 5. The ORTEP plot of $\mathbf{1 b}$ with atoms drawn as $30 \%$ thermal ellipsoids. The complete asymmetric unit is shown. Selected atoms are labeled. Hydrogen bonds are drawn as dashed lines.

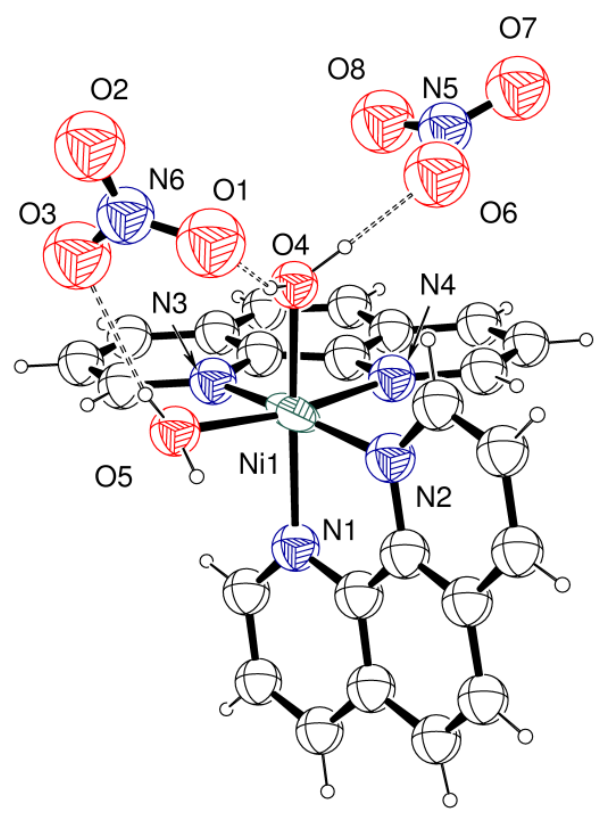

Although the crystal was weakly diffracting beyond $d=1.05 \AA$ and only a very limited number of data frames could be collected before the crystal decomposed, it was possible to refine a structure for 1b against the available data. Approximately $30 \%$ of the available data were recorded to a resolution of $1.05 \AA$. Limitations in the data quality and coverage necessitated the use of relatively severe restraints on the molecular geometry, including rigid body restraints on the 1,10-phen molecules. Hydrogen atoms were all placed at calculated positions. The final structure determination is rather poor quality ( $R=12.53 \%$ for the data with $I>4 \sigma_{\mathrm{I}}$ ) but gives very useful chemical information about the structure of $\mathbf{1 b}$. Full details are given in the Supplementary Material.

The structure of $\mathbf{1 b}$ is in good agreement with the prediction of a $Z^{\prime}=1$ structure composed of hydrogen bonding chains similar to those in $\mathbf{1}$. The overall structure is similar to that of $\mathbf{1}$. The key feature of $\mathbf{1 b}$ is that it contains only one chemically unique chain, which is illustrated in Figure 6. Using the notation for the chains in $\mathbf{1}$, these chains are similar to those labelled type $A$ in Figure 2. Inter-chain $\pi-\pi$ interactions are still present between 1,10-phen ligands at a distance of about $3.43 \AA$. It is notable that the differences in the structures are due to ordering of nitrate positions within $\mathbf{1}$, while in 1b only two nitrate positions are observed. However, the nitrates in $\mathbf{1 b}$ were rather poorly located, suggesting a high degree of positional and rotational disorder in $\mathbf{1 b}$, reinforcing the idea that the phase change from $\mathbf{1}$ to $\mathbf{1 b}$ happens when there is sufficient energy to remove ordering of nitrate positions. It may be possible to undertake further studies employing synchrotron radiation to obtain a better structure for $\mathbf{1 b}$ in the short time ( $\mathrm{ca} .60$ minutes) available before it decomposes at $308 \mathrm{~K}$. 
Figure 6. Illustration of the single type of hydrogen-bonding chain found within $\mathbf{1 b}$; $i=x,-0.5-y,-0.5-z ; i i=x,-0.5-y, 0.5+z$. Hydrogen bonds are drawn as dashed lines.

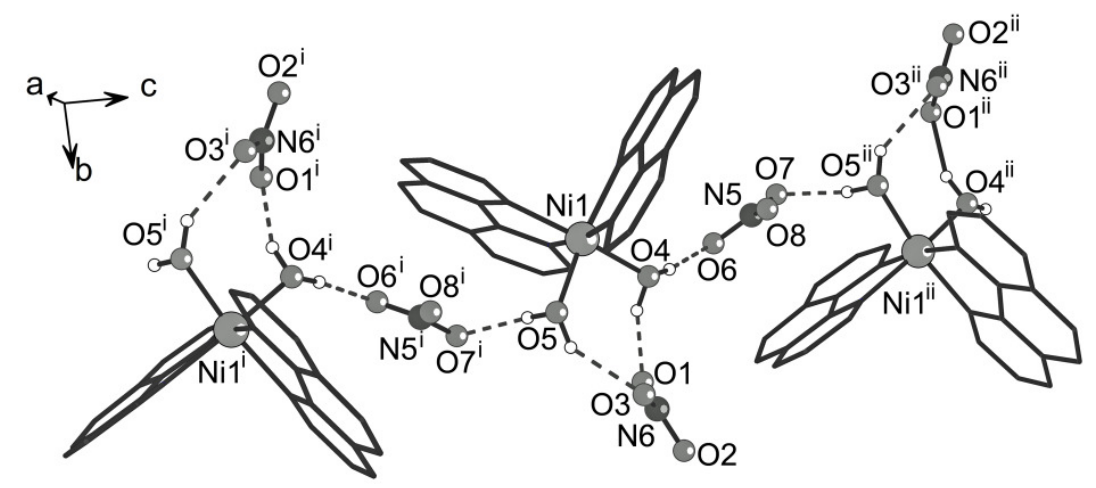

\section{Experimental Section}

\subsection{Crystal Growth and Characterization}

In order to grow single crystals of $\mathbf{1}$, an ethanolic solution of the organic ligand (solution A) was first prepared by dissolving $0.495 \mathrm{~g}(2.47 \mathrm{mmol})$ of 1,10-phenanthroline $\left(\mathrm{C}_{12} \mathrm{H}_{8} \mathrm{~N}_{2}\right.$; Fluka, 99\%) in $15.00 \mathrm{~cm}^{3}$ of ethyl alcohol $\left(\mathrm{C}_{2} \mathrm{H}_{5} \mathrm{OH}\right.$; Merck, 99.9\%). The aqueous solution of $\mathrm{Ni}^{2+}$ (solution B) was prepared by dissolving $1.4947 \mathrm{~g}(5.09 \mathrm{mmol})$ nickel(II)nitrate $\left(\mathrm{Ni}\left(\mathrm{NO}_{3}\right)_{2} \cdot 6 \mathrm{H}_{2} \mathrm{O}\right.$; Carlo Erba, 99\%) in $30.00 \mathrm{~cm}^{3}$ of aqueous potassium hydroxide solution (KOH; Merck, 85\%) with the concentration of $0.167 \mathrm{~mol} \mathrm{dm}^{-3}$. A portion of $1.50 \mathrm{~cm}^{3}$ of solution $B$ was gently loaded into a glass tube of $5 \mathrm{~mm}$ in diameter and $10 \mathrm{~cm}$ in length, followed by another $1.50 \mathrm{~cm}^{3}$ of solution $A$. The purple crystals of 1 appeared at the boundary between solution $A$ and solution $B$ after leaving the tube undisturbed for about a month at room temperature. Following drying, the resulting crystals were visible homogeneous and well dispersed, rather than forming aggregates.

\subsection{Crystal Structure Determination}

A good sized crystal, visibly representative of the bulk product, was selected for diffraction measurements. A data set of 28015 independent reflections was collected in a range of $1.36 \leq \theta /^{\circ} \leq 25.89$ from a $0.60 \times 0.32 \times 0.24 \mathrm{~mm}^{3}$ purple block crystal of 1 using a Stoe IPDS2 diffractometer and Stoe $X$-Area software [20]. The temperature of the crystal was controlled during data collection using an Oxford Instruments nitrogen gas cryostream and set to $120 \mathrm{~K}$ for the first data collection. Two tranches of data with different counting times were collected. Each frame employed a $1^{\circ} \omega$-rotation. The first run consisted of 158 images with a counting time of $48 \mathrm{~s}$ per frame. The second run consisted of 123 images with a counting time of $390 \mathrm{~s}$ per frame. There was significant overlap between the two runs in reciprocal space to allow reliable scaling of the two tranches to give a single data file. The use of two different counting times was designed to obtain the most reliable signal to noise ratio for both the strong and weak reflections.

A face indexed absorption correction was applied to the collected data within the Stoe $X$-RED software using the Tompa method [21,22]. The data were then reduced and merged giving 15,842 
reflections with $\mathrm{I}>2 \sigma(\mathrm{I})$ and an internal $R$ of 0.0862 . The structure was solved by direct methods using SHELXS-97 and full-matrix least-squares refinement was carried out with SHELXL-97 via the WinGX program interface [23,24]. All non-hydrogen atoms were refined with anisotropic displacement parameters. Despite the complexity of the structure it was not necessary to restrain bond distances or angles involving any of the non-hydrogen atoms. Hydrogen atoms were unambiguously located within Fourier difference maps once all other atoms had been identified. Those of the 1,10-phen ligands were places at geometrically calculated positions using a riding model with $\mathrm{C}-\mathrm{H}$ bond length $0.95 \AA$ A. The hydrogen atoms attached to water were placed from the Fourier difference maps, subject to sensible $\mathrm{O}-\mathrm{H}$ bond length restraints (target distance $0.86 \AA$ ) and where necessary geometric restraints to generate chemically sensible hydrogen bonds. Displacement parameters for the 24 independent hydrogen atoms of water were divided into two groups dependent upon the magnitude of the electron density at that point in a Fourier map. Within each group, a single isotropic displacement parameter was applied for all atoms. Crystallographic details for structural solution and refinement are summarized in Table 1.

The rms deviation of the bond lengths in the pseudo-equivalent fragments is a good indicator of the quality of the refinement [25] with large deviations indicative of an incorrect model. Here the rms deviation is $0.018 \AA$ for the 18 equivalent bonds in the about $(\mathrm{Ni}-\mathrm{O}$ and $\mathrm{Ni}-\mathrm{N})$ in the $\left[\mathrm{Ni}(1,10-\mathrm{phen})_{2}\right.$ $\left.\left(\mathrm{H}_{2} \mathrm{O}\right)_{2}\right]^{2+}$ cations. Similarly, the rms deviation of equivalent bond lengths from their mean, may also be used as a guide to the quality of fit. Here, the rms deviations from the mean are $0.014 \AA$ for Ni-O bonds and $0.009 \AA$ for Ni-N bonds. These small discrepancy values give confidence in the model.

The data collection strategy for the higher temperature $\mathrm{X}$-ray diffraction measurements was similar. For the data collection at $291 \mathrm{~K}$, three tranches of data with significant overlap but different counting times were collected, corrected for absorption, and merged to give a single set of intensity data. The data collection at $308 \mathrm{~K}$ recorded a single set of 20 frames. The unit cell was determined from these and the data were integrated using standard techniques and corrected for crystal decay.

\subsection{Infrared Spectroscopy}

The Fourier-transform IR spectrum of ground crystals of $\mathbf{1}$ was recorded using a Perkin-Elmer Paragon 1000 FT-IR instrument $\left(4,000-400 \mathrm{~cm}^{-1}\right.$, resolution $\left.0.5 \mathrm{~cm}^{-1}\right)$ using $\mathrm{KBr}$ (BDH 98.5\%) disks.

\subsection{Chemical Analysis}

Analytical data were collected at the University of Hull by Mrs C. Kennedy using a Fisons EA 1108 CHN analyzer.

\subsection{Thermal Analysis}

Thermogravimetry: samples were placed into platinum pans, loaded into a Mettler-Toledo TGA/DSC1 Thermogravimetric Analyzer and heated under a flow of nitrogen from room temperature to $1000{ }^{\circ} \mathrm{C}$ at a ramp rate of $10{ }^{\circ} \mathrm{C} \mathrm{min}^{-1}$. 


\section{Conclusions}

The crystal structure of $\left[\mathrm{Ni}(1,10 \text {-phen })_{2}\left(\mathrm{H}_{2} \mathrm{O}\right)_{2}\right]\left(\mathrm{NO}_{3}\right)_{2}$ at low temperature is markedly more complicated than other similar compounds because of the hydrogen bonding arrangement formed between the metal complexes and nitrate. Four similar but distinct types of hydrogen-bonded chains are found within 1. The differences between the chains have a direct impact on the crystal packing within 1. It is these small differences that generate the complex asymmetric unit. The low temperature crystal structure is found to persist at room temperature $(291 \mathrm{~K})$, but heating the sample to $308 \mathrm{~K}$ leads to a simplification of the structure associated with removal of the ordering of nitrate. The change from complex to simple structure upon heating is not unusual in structural chemistry, but here the change arises from differences in the hydrogen bonding arrangements rather than from a change in the coordination of the metal.

\section{Acknowledgments}

This work is financially supported by the Thailand Research Fund and the National Research University Project under Thailand's office of the Higher Education Commission. Y. Chimupala thanks the Development and the Development and Promotion of Science and Technology Talent Project, and the Center of Excellence for Innovation in Chemistry (PERCH-CIC) for Graduate Scholarships.

\section{References and Notes}

1. Steed, J.W. Should solid-state molecular packing have to obey the rules of crystallographic symmetry? CrystEngComm 2003, 5, 169-179

2. Bernstein, J.; Dunitz, J.D.; Gavezzotti, A. Polymorphic Perversity: Crystal Structures with Many Symmetry-Independent Molecules in the Unit Cell. Cryst. Growth Des. 2009, 8, 2011-2018.

3. Summers, L.A. The Phenanthrolines. In Advances in Heterocyclic Chemistry; Katritzky, A.R., Boulton, A.J., Eds.; Academic Press: New York, NY, USA, 1978; Volume 22, pp. 1-69.

4. Sammes, P.G.; Yahioglu, G. 1,10-Phenanthroline: A versatile ligand. Chem. Soc. Rev. 1994, 23, 327-334.

5. Cooke, M.W.; Chartrand, D.; Hanan, G.S. Self-assembly of discrete metallosupramolecular luminophores. Coord. Chem. Rev. 2008, 252, 903-921.

6. Gimeno, N.; Vilar, R. Anions as templates in coordination and supramolecular chemistry. Coord. Chem. Rev. 2006, 250, 3161-3189.

7. Tang, X.Y.; Qiu, Y.C.; Sun, F.; Yue, S.T. Diaquabis $\left(1,10-\right.$ phenanthroline- $\left.\kappa^{2} N, N^{\prime}\right)$ nickel(II) diperchlorate 0.4-hydrate. Acta Crystallogr. 2007, E63, m2515.

8. Zhu, L.; Zhang, L.H.; Liu, B.Y.; An, Z. Crystal structure of diaquabis(1,10phenanthroline)nickel(II) sulfate hydrate (1:5.6), $\left[\mathrm{Ni}\left(\mathrm{H}_{2} \mathrm{O}\right)_{2}\left(\mathrm{C}_{12} \mathrm{H}_{8} \mathrm{~N}_{2}\right)_{2}\right]\left[\mathrm{SO}_{4}\right] \cdot 5.6 \mathrm{H}_{2} \mathrm{O} . \quad Z$. Kristallogr.-New Cryst. Struct. 2006, 221, 451-452.

9. Ferbinteanu, M.; Cimpoesu, F.; Mariusandruh, A.; Rochon, F.D. Solid-state chemistry of $\left[\mathrm{Ni}(\mathrm{AA})_{3}\right]\left[\mathrm{PdCl}_{4}\right] \cdot \mathrm{nH}_{2} \mathrm{O}$ complexes (AA = bipy, phen) and crystal structures of cis-diaquabis(phenanthroline)nickel(II) tetrachlorozincate and cis-dichloro-bis(bipyridine)nickel(II).

Polyhedron 1998, 17, 3671-3679. 
10. Khan, M.I.; Chang, Y.D.; Chen, Q.; Salta, J.; Lee, Y.S.; O’Connor, C.J.; Zubieta, J. Synthesis and characterization of binuclear oxo-vanadium complexes of carbon oxoanion ligands. Crystal structures of the binuclear vanadium(IV) complex $\left(\mathrm{NH}_{4}\right)\left[\mathrm{V}_{2} \mathrm{O}_{2}(\mathrm{OH})\left(\mathrm{C}_{4} \mathrm{O}_{4}\right)_{2}\left(\mathrm{H}_{2} \mathrm{O}\right)_{3}\right] \cdot \mathrm{H}_{2} \mathrm{O}$, of the mixed-valence vanadium(V)/vanadium(IV)-squarate species $\left[\left(\mathrm{n}^{-} \mathrm{C}_{4} \mathrm{H}_{9}\right)_{4} \mathrm{~N}\right]\left[\mathrm{V}_{2} \mathrm{O}_{3}\left(\mathrm{C}_{4} \mathrm{O}_{4}\right)_{2}\left(\mathrm{H}_{2} \mathrm{O}\right)_{3}\right]$ $\cdot 3 \mathrm{H}_{2} \mathrm{O}$ and $\left[\left(\mathrm{C}_{4} \mathrm{H}_{9}\right)_{4} \mathrm{~N}_{4}\left[\mathrm{~V}_{4} \mathrm{O}_{6}\left(\mathrm{C}_{4} \mathrm{O}_{4}\right)_{5}\left(\mathrm{H}_{2} \mathrm{O}\right)_{4}\right] \cdot 6 \mathrm{H}_{2} \mathrm{O}\right.$, and of the binuclear vanadium(IV)-oxalate species $\left[\mathrm{V}_{2} \mathrm{O}_{2} \mathrm{Cl}_{2}\left(\mathrm{C}_{2} \mathrm{O}_{4}\right)\left(\mathrm{CH}_{3} \mathrm{OH}\right)_{4}\right] \cdot 2 \mathrm{Ph}_{4} \mathrm{PCl}$. Inorg. Chem. 1994, 33, 6340-6350.

11. Kumagai, H.; Endo, M.; Kawata, S.; Kitagawa, S. A mixed-valence tetranuclear vanadium(IV, V) complex, $\left[\mathrm{V}_{4} \mathrm{O}_{4}(\mu-\mathrm{OEt})_{2}(\mu-\mathrm{O})_{2}(\mathrm{OEt})_{4}(\mathrm{phen})_{2}\right]$. Acta Crystallogr. 1996, C52, 1943-1945.

12. Bernstein, J.; Davis, R.E.; Shimoni, L.; Chang, N.-L. Patterns in hydrogen bonding: functionality and graph set analysis in crystals. Angew. Chem. Int. Ed. Engl. 1995, 34, 1555-1573

13. Jeffrey, G.A. An Introduction to Hydrogen Bonding; Oxford University Press: Oxford, UK, 1997.

14. Harlow, R.L. Troublesome Crystal Structures: Prevention, Detection, and Resolution. J. Res. Nat. Inst. Stand. Technol. 1996, 101, 327-339.

15. Théorêt, A.; Sandorfy, C. Infrared spectra and crystalline phase transitions of ammonium nitrate. Can. J. Chem. 1964, 42, 57-62.

16. Baran, J.A.; Drozd, M.A.; Ratajczak, H. Polarised IR and Raman spectra of monoglycine nitrate single crystal. J. Mol. Struct. 2010, 976, 226-242.

17. Atanassova, M.S.; Dimitrov, G.D. Synthesis and spectral characterization of novel compounds derived from 1,10-phenanthroline, lead(II) and tetrabutylammonium tetrafluoroborate. Spectrochim. Acta A 2003, 59, 1655-1662.

18. Thornton, D.A.; Watkins, G.M. A full vibrational assignment $\left(4000-50 \mathrm{~cm}^{-1}\right)$ of 1,10-phenanthroline and its perdeuterated analogue. Spectrochim. Acta A 1991, 47, 1085-1096.

19. Liu, Q.Y.; Liu, Q.S.; Zhao, Q.R. Diaqua(1,10-phenanthrolin-2-ol)nickel(II) dinitrate. Acta Cryst. 2009, E65, m883.

20. X-AREA, Version 1.18; Stoe \& Cie: Darmstadt, Germany, 2002

21. X-RED32 Version 1.04; Stoe \& Cie: Darmstadt, Germany, 2002.

22. de Meulener, J.; Tompa, H. The absorption correction in crystal structure analysis. Acta Crystallogr. 1965, 19, 1014-1018.

23. Sheldrick G.M. A short history of SHELX. Acta Crystallogr. 2008, A64, 112-122

24. Farrugia, L.J. WinGX suit for small-molecule single-crystal crystallography. J. Appl. Crystallogr. 1999, 32, 837-838.

25. Collins A.; Cooper R.I.; Watkin D.J. Structure matching: Measures of similarity and pseudosymmetry. J. Appl. Crystallogr. 2006, 39, 842-849.

(C) 2011 by the authors; licensee MDPI, Basel, Switzerland. This article is an open access article distributed under the terms and conditions of the Creative Commons Attribution license (http://creativecommons.org/licenses/by/3.0/). 